\title{
SUBTALAR STRESS RADIOGRAPHY USING FORCED DORSIFLEXION AND SUPINATION
}

\author{
TOMOO ISHII, SHUMPEI MIYAGAWA, TORU \\ FUKUBAYASHI, KOICHIRO HAYASHI \\ From the University of Tsukuba, Japan
}

$\mathbf{W}^{\mathrm{c}}$ e investigated a new method of stress radiography of the subtalar joints using forced maximum dorsiflexion of the ankle in a supinated position. We measured transposition of the lateral process of the talus at the posterior subtalar joint in lateral views of normal amputated ankles, normal control subjects and patients with recurrent ankle sprains. The mean displacement in the control groups $(n=36)$ was $29.9 \%$, significantly different from the 43.0\% in patients with recurrent ankle sprains (n= 24).

In the amputated specimens with intact ligaments movement was similar to that in normal subjects. Section of the calcaneofibular and the interosseous ligaments allowed much the same movement as in patients with recurrent ankle sprains.

The new method is simple and useful for detecting subtalar instability.

J Bone Joint Surg [Br] 1996;78-B:56-60.

Received 6 September 1994; Accepted 23 December 1994

Subtalar instability is not common and has been difficult to quantify because of the lack of a stress radiographic method similar to the anterior-drawer and talar tilt tests for talocrural instability. We describe a simple quantitative technique for diagnosing subtalar instability.

\section{MATERIALS AND METHODS}

Experimental investigation. Six freshly frozen legs amputated for malignant tumour, arterial occlusion or trauma, from patients of a mean age of 57.5 years (41 to 81), were

T. Ishii, MD, Lecturer

S. Miyagawa, MD, Lecturer

T. Fukubayashi, MD, Assistant Professor

K. Hayashi, MD, Professor

Department of Orthopaedic Surgery, Institute of Clinical Medicine, University of Tsukuba, 1-1-1 Tennohdai, Tsukuba, Ibaraki 305, Japan.

Correspondence should be sent to Dr T. Ishii.

(C)1996 British Editorial Society of Bone and Joint Surgery 0301-620X/96/11029\$2.00

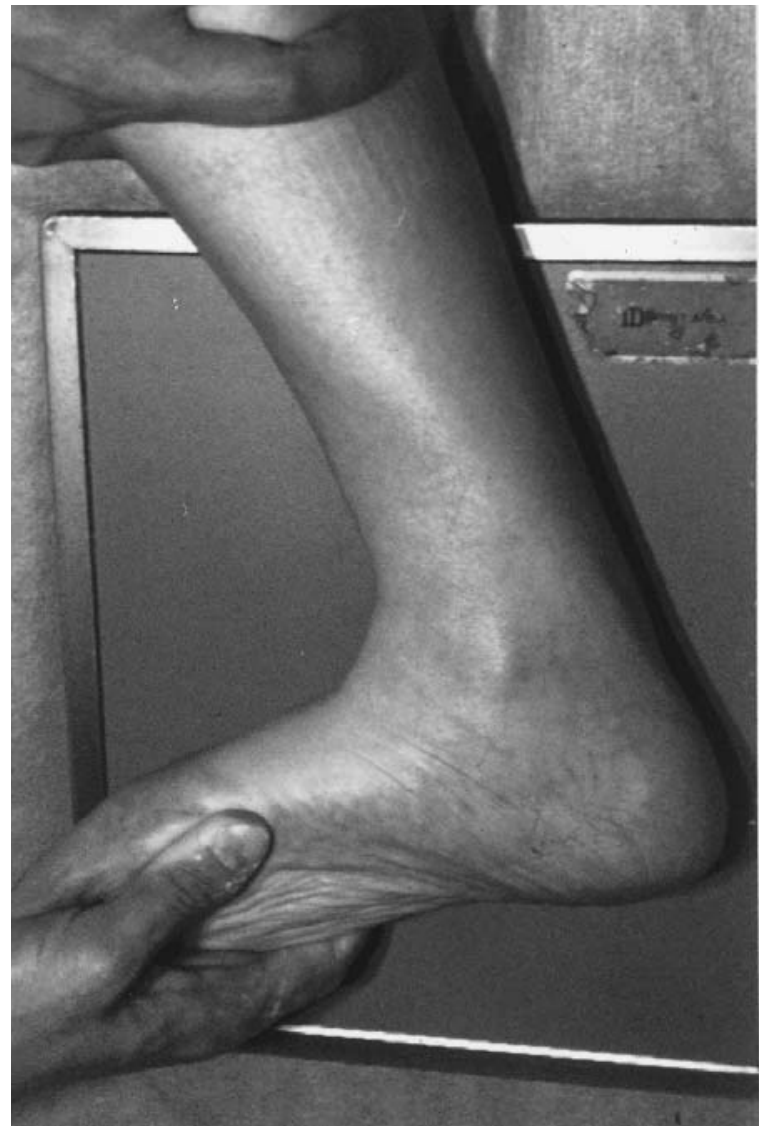

Fig. 1

A subtalar stress view was obtained in a mediolateral projection in forced maximum dorsiflexion, with supination of the foot.

dissected to demonstrate intact anterior talofibular, calcaneofibular and interosseous ligaments. Stress radiographs were taken before section of any ligaments $(n=6)$, after section of the calcaneofibular ligament only $(n=3)$, or the interosseous ligament only $(n=3)$, and after section of both ligaments $(n=6)$. In another trial we also studied the effect of additional section of the anterior talofibular ligament in each group.

Clinical study. The control group was 36 ankles in 18 normal subjects, 9 men and 9 women, who had no history of any previous ankle sprain and showed no evidence of general joint laxity. Their mean age was 23.5 years (19 to 32).

The patient group comprised 18 women all of whom had 


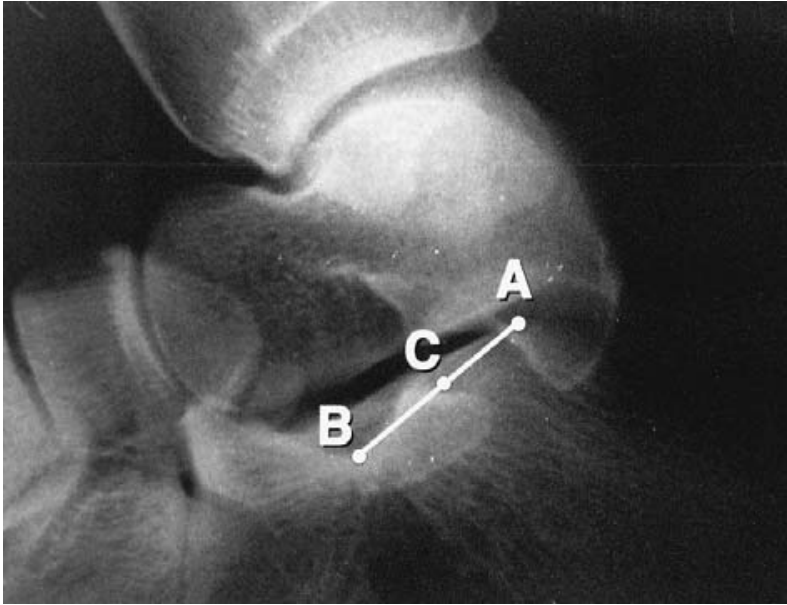

Fig. 2a

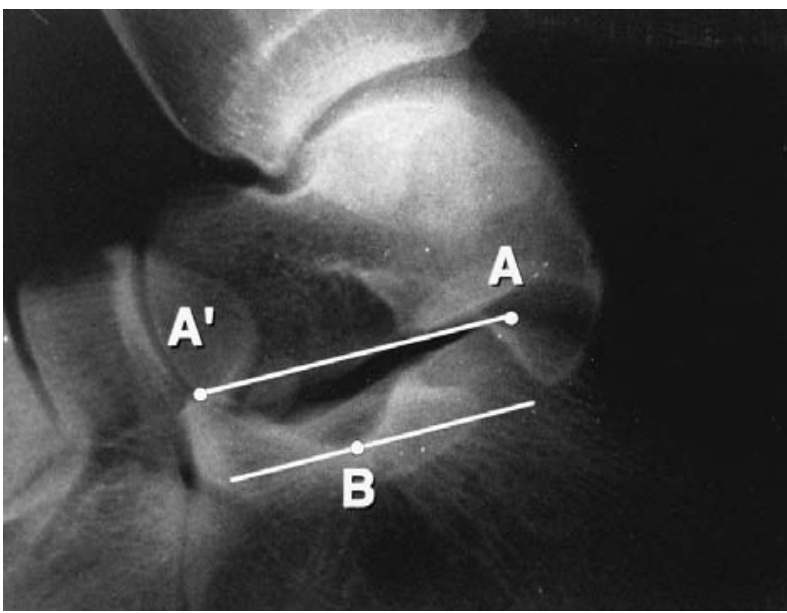

Fig. 2c

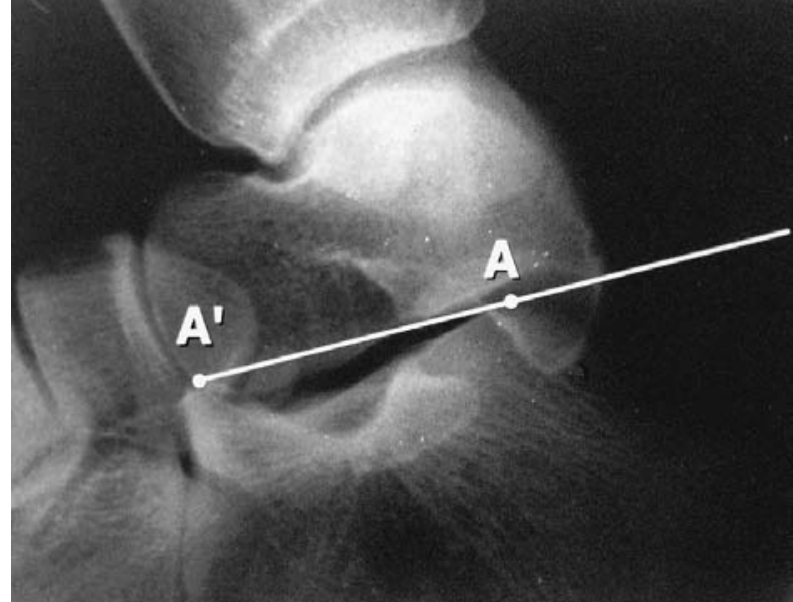

Fig. 2b

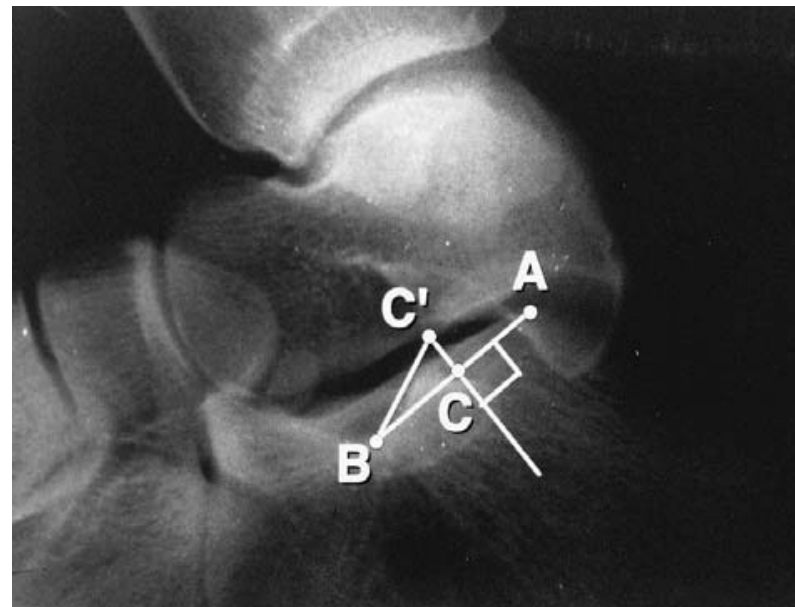

Fig. 2d

Determination of the points A, B and C (a). Point A is the point of intersection of a tangential line from the tip of the anterior process of the calcaneus (A') to the posterior facet (b). Point B is at the bottom of the calcaneal depression just anterior to the posterior facet (c). Point $\mathrm{C}$ is the intersection between line $\mathrm{AB}$ and a perpendicular from point $\mathrm{C}^{\prime}$ at the tip of the talar lateral process. When the three points are determined, $\mathrm{LP} / \mathrm{PF}$ is the percentage ratio of $\mathrm{BC}$ over $\mathrm{AB}(\mathrm{d})$.

had more than three severe ankle sprains on one side. Each sprain had prevented sports activity for at least three days. Six patients had had bilateral recurrences of this nature and only three had had no previous ankle sprain on one side. Their mean age was 23.4 years (17 to 42 ) and 16 of them played competitive sport. Ten of the 18 patients showed evidence of general joint laxity.

In both groups, stress radiographs were taken of both sides. The patient group was subdivided according to the frequency of ankle sprains. Patient control ankles $(n=3)$ had had no previous sprains. In low-frequency sprains $(n=9)$ there had been one or two episodes, in low-frequency recurrent sprains $(n=11)$ three to seven episodes and in high-frequency recurrent sprains $(n=13)$ eight or more episodes.

Technique of stress radiography. Mediolateral views of the ankle are taken with forced manual maximum dorsi- flexion of the ankle (Fig. 1). Care is taken to keep the foot in supination and the knee flexed to more than a right ankle.

On each radiograph we measure the relative position of the lateral process of the talus at the posterior articular facet of the calcaneus (LP/PF). In a pronated relaxed position, the lateral process of the talus is opposite a depression just anterior to the facet on the calcaneus. In forced dorsiflexion with supination of the ankle this process moves posteriorly.

Three points are marked on the radiograph: point $\mathrm{A}$ is the peak of the posterior facet of the calcaneum, point $B$ is the bottom of the depression just anterior to the facet and point $\mathrm{C}$ is the tip of the lateral process of the talus as projected on to the line AB (Fig. 2a). The peak of the posterior calcaneal facet is difficult to define, and we therefore take point $A$ at the intersection of the tangential line from the tip of the 


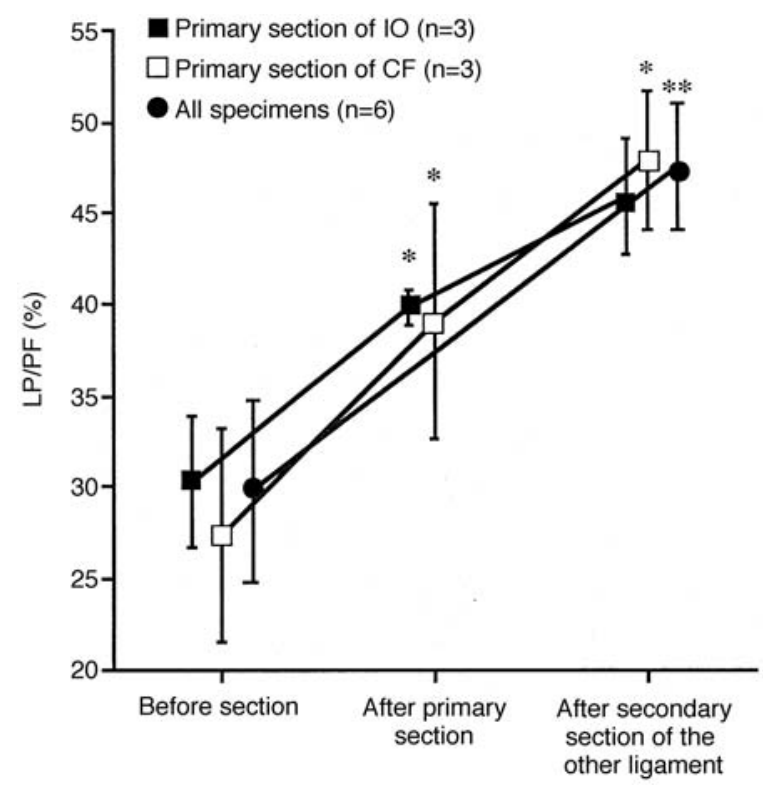

Fig. 3

Results of the experimental study on amputated ankles. Of the six specimens, three had primary section of either the interosseous ligament (IO) or the calcaneofibular ligament (CF). The LP/PF increased proportionately at each step $(*=p<0.05$ compared with the previous stage, $* *=\mathrm{p}<0.001$ compared with the previous stage).

Table I. Measurement of LP/PF (\%; mean \pm SD) in all groups

\begin{tabular}{ll}
\hline Group & LP/PF \\
\hline Control $(\mathrm{n}=36)$ & $29.9 \pm 9.0$ \\
Male control $(\mathrm{n}=18)$ & $27.9 \pm 9.6$ \\
Female control $(\mathrm{n}=18)$ & $32.0 \pm 8.1$ \\
Non-recurrent sprains $(\mathrm{n}=12)$ & $39.7 \pm 7.9^{*}$ \\
Patient control $(\mathrm{n}=3)$ & $36.9 \pm 4.9$ \\
Low-frequency sprains $(\mathrm{n}=9)$ & $40.6 \pm 8.7 \dagger$ \\
Recurrent sprains $(\mathrm{n}=24)$ & $43.0 \pm 9.2^{*}$ \\
Low-frequency recurrent sprains $(\mathrm{n}=11)$ & $40.6 \pm 7.9^{*}$ \\
High-frequency recurrent sprains $(\mathrm{n}=13)$ & $45.0 \pm 10.0^{*}$ \\
\hline
\end{tabular}

$* \mathrm{p}<0.001$ for difference from controls

$\dagger \mathrm{p}<0.01$ anterior process of the calcaneus (A') to the posterior facet (Fig. 2b). The bottom of the depression (B) in the calcaneus is defined as that most distant from the line AA' (Fig. 2c). Point $\mathrm{C}$ is on the projected line $\mathrm{AB}$ opposite the tip of the talar lateral process $\left(C^{\prime}\right)$ (Fig. 2d). The percentage ratio of the line $\mathrm{BC}$ of the line $\mathrm{AB}$ gives the $\mathrm{LP} / \mathrm{PF}$. All the lines and points were determined by a digitiser.

Statistical significances were calculated for the experimental investigation by the paired $t$-test and for the clinical investigation by Student's $t$-test.

\section{RESULTS}

In the experimental investigation, the mean LP/PF before section of the ligaments was $29.5 \%$. Section of both the calcaneofibular ligament and the interosseous ligament, increased this to $47.2 \%(\mathrm{p}<0.001)$ (Fig. 3). Primary section of the interosseous ligament in three ankles gave an increase from $31.5 \%$ to $40.3 \%(\mathrm{p}<0.05)$ and after adding section of the calcaneofibular ligament to $46.5 \%$ ( $\mathrm{p}$ value of this increase $=0.06$ ).

Primary section of the calcaneofibular ligament in three ankles increased movement from $27.5 \%$ to $39.1 \%$ $(\mathrm{p}<0.05)$ and after adding section of the interosseous ligament, to $47.9 \%(\mathrm{p}<0.05)$. Section of the anterior talofibular ligament did not significantly influence the percentage LP/PF at any stage.

In the healthy control group, the mean LP/PF was $27.9 \%$ in males and $32.0 \%$ in females (NS; Table I, Fig. 4a). In patients with non-recurrent sprains the mean movement was $39.7 \%$ and in the recurrent sprain group $43.0 \%$ (both $\mathrm{p}<0.001$ for difference from controls, Table I; Fig.4b). There was a tendency for increasing LP/PF with increasing number of sprains (Fig. 5). One of the patient control groups had general joint laxity and movement of $42.3 \%$ at the uninjured ankle; the other two showed $32.8 \%$ and $35.5 \%$.

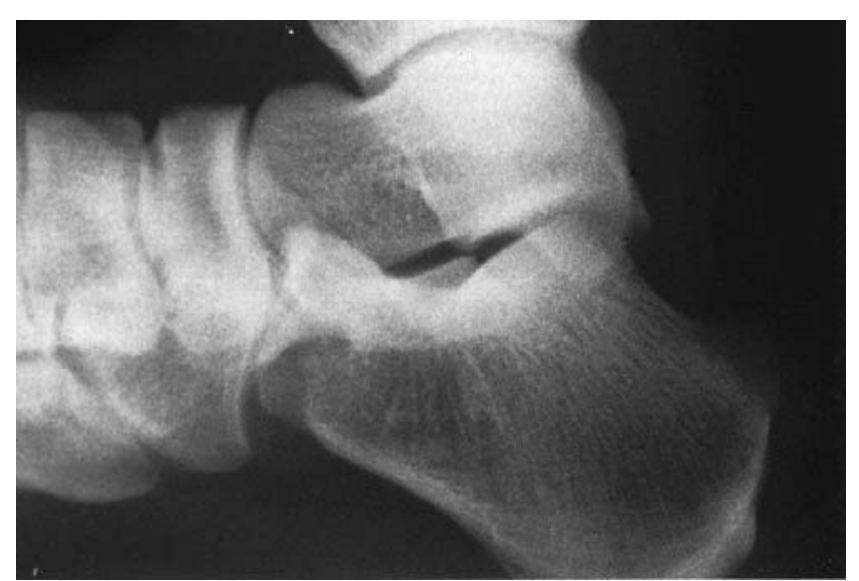

Fig. 4a

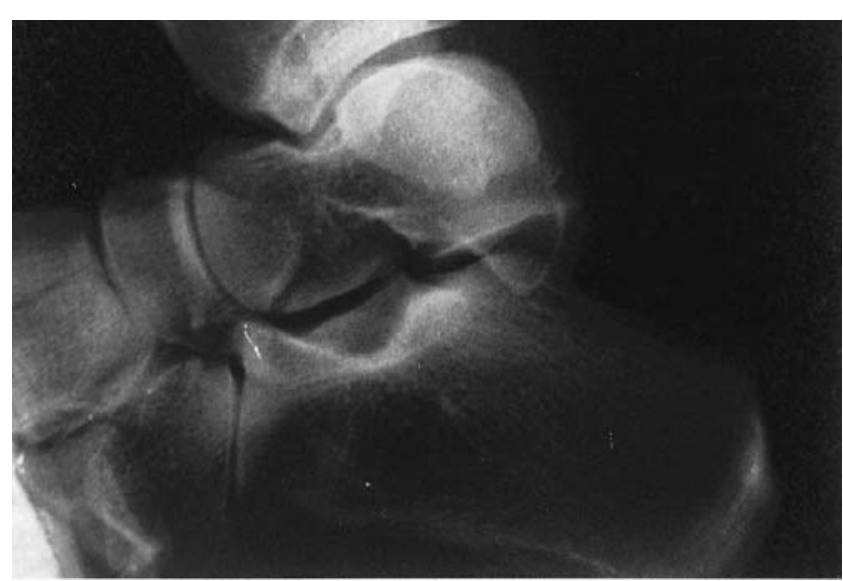

Fig. 4b

Subtalar stress radiographs. Figure $4 \mathrm{a}-$ Normal female control with LP/PF of $25.8 \%$. Figure $4 \mathrm{~b}-$ Patient with high-frequency recurrent sprains and general joint laxity. The LP/PF was $56.8 \%$. 


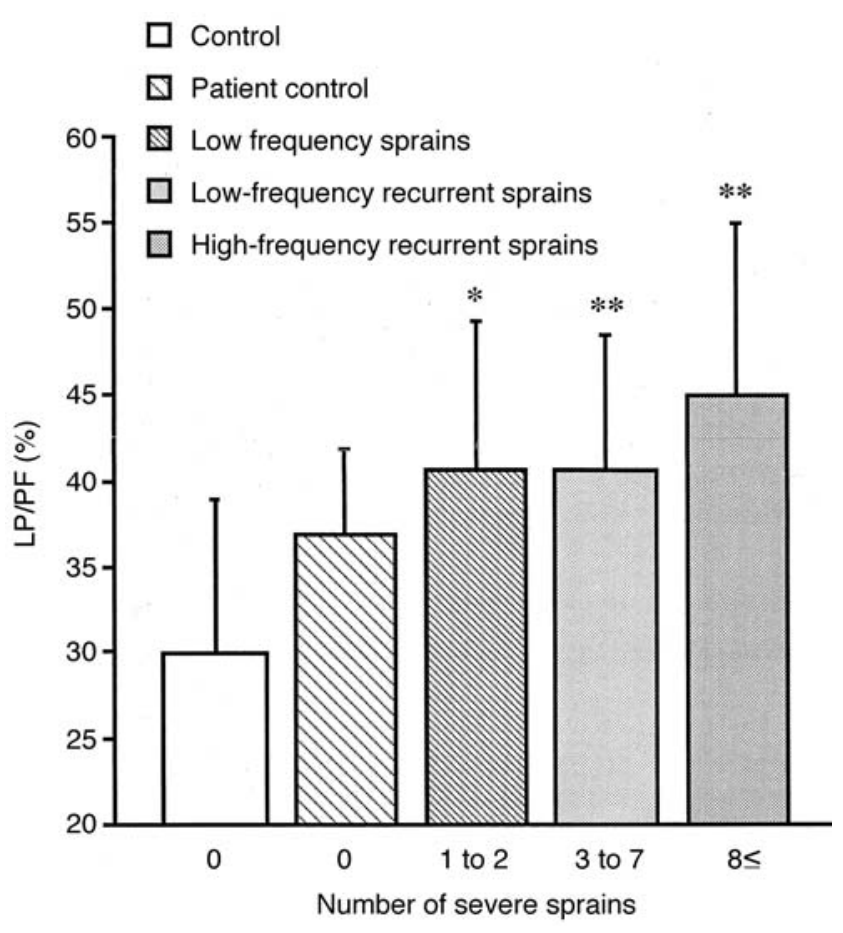

Fig. 5

Relationship between LP/PF and the number of sprains. LP/PF increased as the number of sprains increased $\left(^{*}=\mathrm{p}<0.01\right.$ compared with control values; $* *=\mathrm{p}<0.001$ compared with control values).

We considered that LP/PF of more than $44 \%$ confirmed mechanical subtalar instability. This was calculated from $47.2 \%$, the mean value for two-ligament section in the experimental investigation, less $3.4 \%$, its standard deviation. Using these criteria, there were two showing subtalar instability in the control group $(6 \%)$, none in the patient control ankles, three in the low-frequency sprain group $(33 \%)$, six in the low-frequency recurrent sprain group

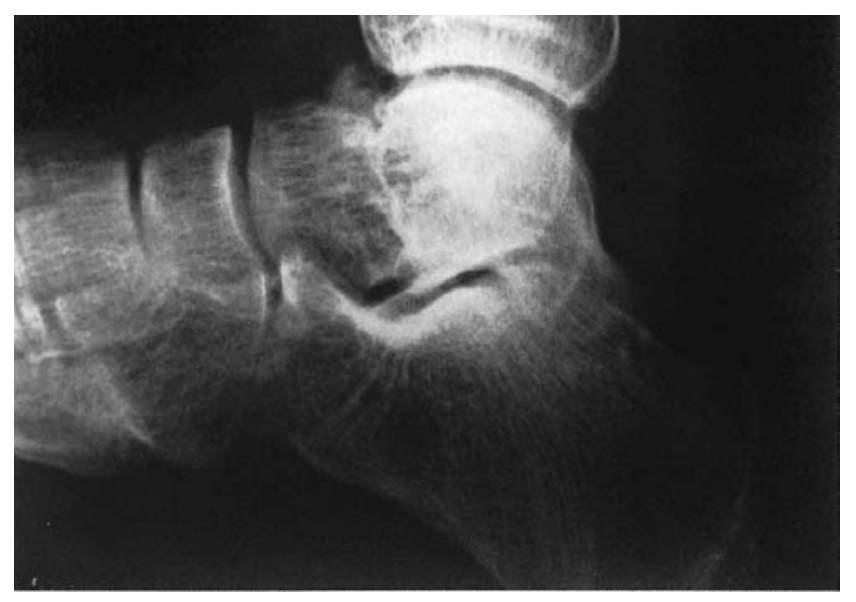

Fig. 6

A patient after a Hawkins type-II fracture-dislocation of the talar neck. The lateral process did not move with subtalar stress and the LP/PF was $13.3 \%$, as against $27.8 \%$ on the normal side.
$(55 \%)$ and ten in the high-frequency recurrent sprain group (77\%). If the criterion for instability is taken as $48 \%$, that is twice the standard deviation in the controls, then the sensitivity falls and the specificity increases.

\section{DISCUSSION}

Several methods for taking the subtalar stress view have been reported, using two types of applied stress, either inversion or anterior drawer. The use of inversion stress tomograms in coronal sections of the ankle using a special forced inversion device was described by Rubin and Witten (1962) and by Brantigan, Pedegana and Lippert (1977). These were theoretical studies and there have been few reports of the clinical application of the method (Clanton 1989). A more popular method is that of the inversion Brodén view (Brodén 1949) which uses inversion stress applied manually to the subtalar joint (Laurin, Ouellet and St-Jacques 1968) to show loss of parallelism at the posterior articular facet. A cadaver study by Heilman et al (1990) showed that an X-ray beam tilted $30^{\circ}$ is best, and that there is a progressive increase in the posterior facet angle as ligaments are sectioned. Clinical studies on a modified method have been reported (Zwipp and Tscherne 1982; Clanton 1989) but do not give quantitative detail for normal subjects or patients with subtalar instability. The mean posterior facet angle in our normal subjects on Brodén inversion views was $8.2^{\circ} \pm 4.2^{\circ}$ (mean $\pm \mathrm{SD}$ ). We consider that the loss of parallelism on the posterior articular facet does not always indicate subtalar instability.

Subtalar stress views using anterior-drawer forces have been described by Kato et al (1988) and by Clanton (1989) who used anteroposterior films of the foot and measured the anterior displacement of the calcaneus on the talus. Meyer et al (1988) described a clinical classification of rupture of the subtalar ligaments, noting that lesions of the interosseous ligament and the calcaneofibular ligament are not always combined and that rupture of the anterior talofibular ligament is often associated. Subtalar stress views using anterior drawer alone may therefore be influenced by talocrural instability.

Subtalar stress views using forced maximum dorsiflexion with supination of the ankle provide a simple and quantitative method, and exclude the factor of talocrural instability. The biomechanical studies of Kjaersgaard-Andersen, Wethelund and Nielsen (1987) and Kjaersgaard-Andersen et al (1988) showed that section of the calcaneofibular ligament allowed increased adduction of the talocalcaneal joint, maximal in maximum dorsiflexion, and that section of the interosseous ligament allowed increased dorsiflexion of the talocalcaneal joint.

There are few articles about the clinical implications of subtalar stress radiography, but our results show a direct relationship between the number of severe sprains and increased subtalar instability.

Another possible use of subtalar stress radiography is in 
the assessment of subtalar stiffness after fractures of the calcaneus or talus, prolonged immobilisation or secondary to talocalcaneal coalition (Fig. 6). Subtalar fixation is commonly in a pronated position, and forced dorsiflexion with supination of the ankle produces only $5 \%$ to $15 \% \mathrm{LP} / \mathrm{PF}$.

It is uncertain whether there are any clinical symptoms specific to subtalar instability, largely because such instability has been difficult to measure. Our method is simple and quantitative, and appears to have adequate sensitivity and specificity, using LP/PF movement of $>44 \%$ as the criterion. Investigation of subtalar instability will benefit from more appropriate methods of subtalar stress radiography.

No benefits in any form have been received or will be received from a commercial party related directly or indirectly to the subject of this article.

\section{REFERENCES}

Brantigan JW, Pedegana LR, Lippert FG. Instability of the subtalar joint: diagnosis by stress tomography in three cases. J Bone Joint Surg [Am] 1977;59-A:321-4.
Brodén B. Roentgen examination of the subtaloid joint in fractures of the calcaneus. Acta Radiol 1949;31:85-91.

Clanton TO. Instability of the subtalar joint. Orthop Clin North Am 1989;20:583-92.

Heilman AE, Braly WG, Bishop JO, Noble PC, Tullos HS. An anatomic study of subtalar instability. Foot and Ankle 1990;10:224-8.

Kato T, Hosokawa M, Yokoi A, Ando C, Hashimoto K. Instability of the subtalar joint. Cent Jpn J Orthop Traumatol 1988;31:1145-6.

Kjaersgaard-Andersen P, Wethelund J-O, Nielsen S. Lateral talocalcaneal instability following section of the calcaneofibular ligament, a kinesiologic study. Foot Ankle 1987;7:355-61.

Kjaersgaard-Andersen P, Wethelund JO, Helmig P, Søballe K. The stabilizing effect of the ligamentous structures in the sinus and canalis tarsi on movements in the hindfoot: an experimental study. Am J Sports Med 1988;16:512-6.

Laurin CA, Ouellet R, St-Jacques R. Talar and subtalar tilt: an experimental investigation. Can J Surg 1968;11:270-9.

Meyer JM, Garcia J, Hoffmeyer P, Fritschy D. The subtalar sprain: a roentgenographic study. Clin Orthop 1988;226:169-73.

Rubin G, Witten M. The subtalar joint and the symptom of turning over on the ankle. Am J Orthop 1962;4:16-9.

Zwipp H, Tscherne H. Die radiologische Diagnostik der Rotationsinstabilität im hintern untern Sprunggelenk. Unfallheilkunde 1982;85: 494-8. 